\title{
REGIONAL COMPARATIVE APPROACHES ON POPULATION AND MAIN DEMOGRAPHIC PHENOMENA - BACAU COUNTY OF ROMANIA VERSUS THE CENTRAL REGION OF THE REPUBLIC OF MOLDOVA
}

\author{
Vasilica-Lăcrămioara Ciomârtan \\ Statistical County Directorate Bacau \\ lacri_vasi@yahoo.com
}

\begin{abstract}
Knowing the whole population, the role and the place of each person in the reproduction of the population, in the economic and social activity, as well as the correlated analysis on age and sex groups is essential in order to ground economic and social policies. The comparative approach, considering the evolution of the population as well as the main demographic phenomena, aims to assess the demographic situation in Bacau County, Romania, as well as in the Central Region of the Republic of Moldova, over a period of 9 years (2007-2015). In order to quantify the complex demographic situation in the two territorial units for statistics, we took into consideration a relatively small number of indicators, the most relevant ones, which should underline the evolution from a demographic point of view.
\end{abstract}

\section{Keywords}

population; median age; demographic vitality; demographic ageing; demographic dependency ratio

\section{JEL Classification}

C19; J11; J13; J19

\section{Introduction}

The comparative approach, considering the evolution of the population as well as the evolution of the main demographic phenomena, aims to assess the demographic situation in Bacau County, Romania, as well as in the Central Region of the Republic of Moldova, over a period of 9 years (2007-2015). In order to quantify the complex demographic situation in the two territorial units for statistics, we took into consideration a relatively small number of indicators, the most relevant ones, which should underline the evolution from a demographic point of view.

The analysis of the changes in the population size, the modifications within its structure on age and gender groups, determining the relevant indicators for demographic vitality, demographic ageing and demographic dependency ratio are a starting point in drawing up an overview of the more or less "dramatic" situations existing in the two areas.

\section{Short methodological presentation}

In order to carry out this comparative analysis, certain methodological aspects need to be clarified, since the different names for certain statistic indicators found in the calculations and the dissemination process in Romania and in the Republic of Moldova are based on the same methodology. 
Thus, the legal permanent resident population calculated and disseminated by the National Institute of Statistics is registered in Moldova as the "stable population"; in fact, this indicator shows the number of people with permanent residence in that area, while the stable population in Romania is known as the "present population" in the Republic of Moldova, showing the number of people living in that area at a certain moment.

The Tempo-Online data base of the NIS (National Institute of Statistics) as well as the data base of the NIS in the Republic of Moldova were the starting point for this analysis which is meant to be a "radiography" of the demographic situation over the period of time 2007-2015 in Bacau County and in the Central Region of the Republic of Moldova.

\section{Statistical analysis of the population by age and gender}

In order to interpret the structure of the population by age groups, three great age groups were taken into consideration: 0-14 years of age, 15-64 years of age and the group aged 65 and over 65 . According to the ratio of these age groups, there are three types of population: young, stationary or adult population and elder.

A ratio under $20 \%$ of the population aged between 0 and 14 , together with the growth in time of the percentages for the other age groups show, in the case of Bacau County, a population that tends to age. The situation is somehow similar in the case of the Central Region of the Republic of Moldova, where the percentage of the young population decreases giving way to the adult population, the percentage of the population over 65 also decreasing.

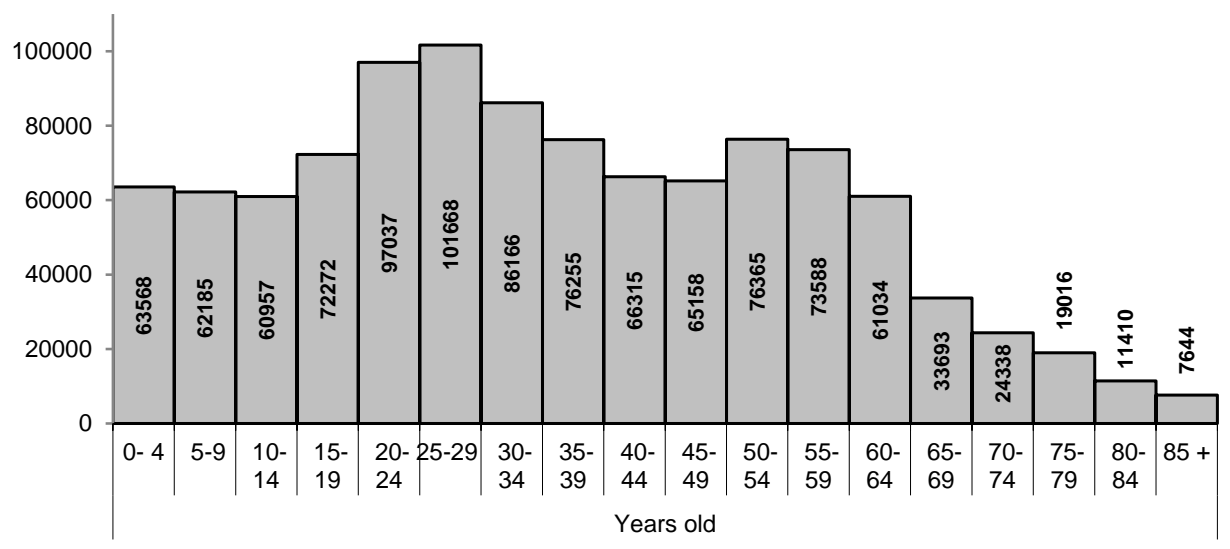

Figure no. 1: Evolution of the structure on age groups for the population with permanent residence in the Central Region (Republic of Moldova) on the 1st of January 2015

Source: processing of the data collected from www.statistica.md 


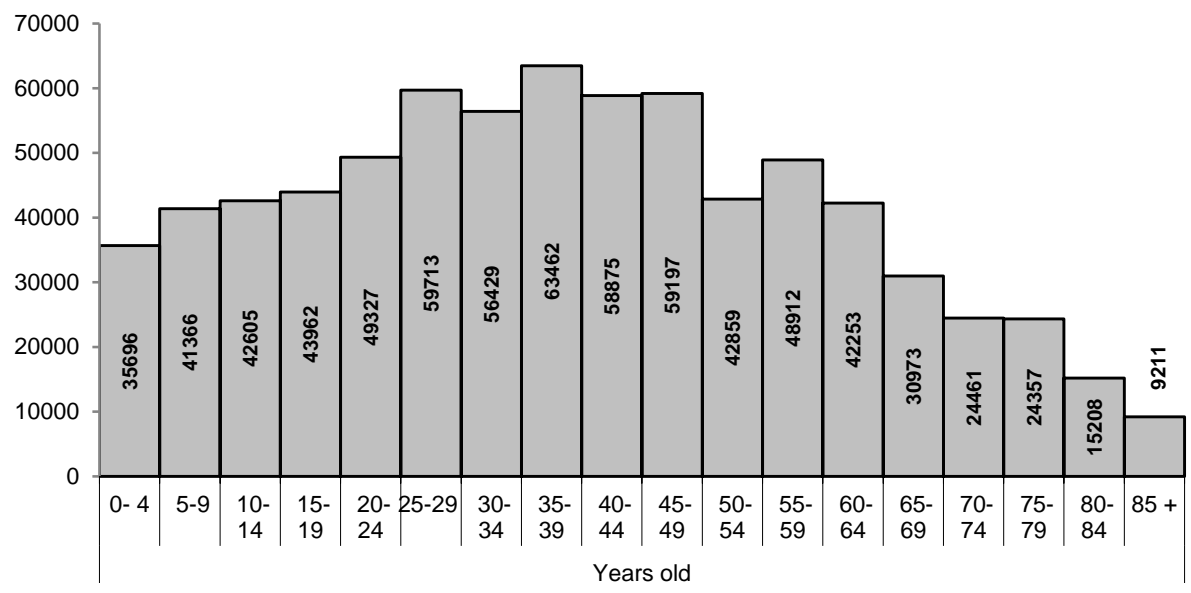

Figure no. 2: Evolution of the structure on age groups for the population with permanent residence in Bacau County (Romania) on the 1st of January 2015 Source: processing of the data collected from www.insse.ro - Tempo-Online

The structure of the population by age groups exhibits characteristic features of the demographic ageing process, mainly caused by declining birth rate, which led to a decrease in the young population in Bacau County from $17.6 \%$ in 2007 to $16.0 \%$ in 2015, while in the Central Region it dropped from $20.0 \%$ in 2007 to $17.6 \%$ in 2015. In parallel, life expectancy increased leading to a greater number and percentage of adult population (15-64 years old) from $69.0 \%$ in 2007 to $70.1 \%$ in 2015 in Bacau County and from $70.7 \%$ in 2007 to $73.3 \%$ in 2015 in the case of the Central Region (Moldova). The elder population in Bacau County increased during the period of time subjected to this analysis from $13.4 \%$ in 2007 to $13.9 \%$ in 2015 , while in the Central Region the percentage is slightly decreasing.

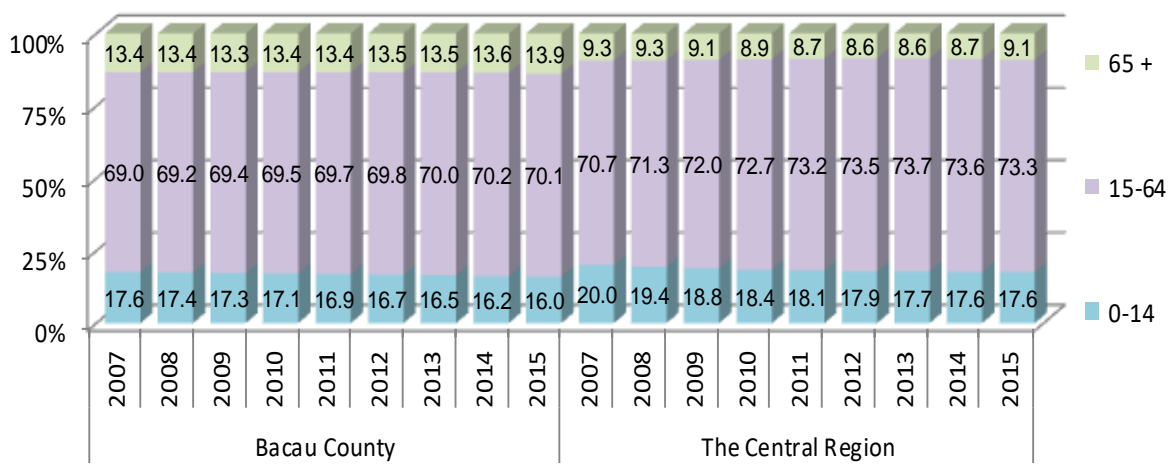

Figure no. 3: Evolution of the structure on major age groups of the population with permanent residence in Bacau County and in the Central Region on the $1^{\text {st }}$ of January (2007-2015) (\%)

Source: processing of the data collected from www.insse.ro and www.statistica.md

The median age is an indicator that divides the population of a certain area into two equal-sized groups, the median age being the middle value. On the level of Bacau 
County, on 1st January 2015, the median age was 38.6 years old, 3.3 years higher than the one registered on 1st January 2007.

If we calculate this indicator for the Central Region, we notice that the median age on 1st January 2015 is 34.2, merely 1.9 years higher compared to the beginning of 2007 .

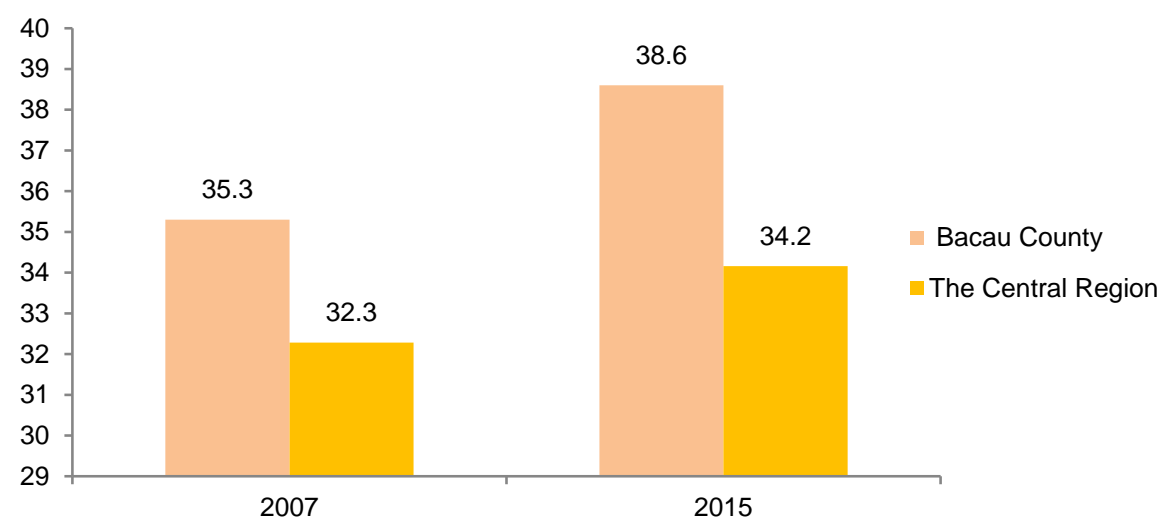

Figure no. 4: Median age of the permanent resident population in Bacau County and in the Central Region on the 1st of January 2007 and 2015

Source: processing of the data collected from www.insse.ro and www.statistica.md

Analyzing the population by gender ratio according to their residence, we can notice that the female population is higher than the male population. While in Bacau County there is an increase in the ratio of the female population from a minimum value of $50.3 \%$ in 2007 to $50.5 \%$ in 2011-2015, in the Central Region, during the whole period subjected to this analysis, the percentage of female population was constant $(51.1 \%)$.

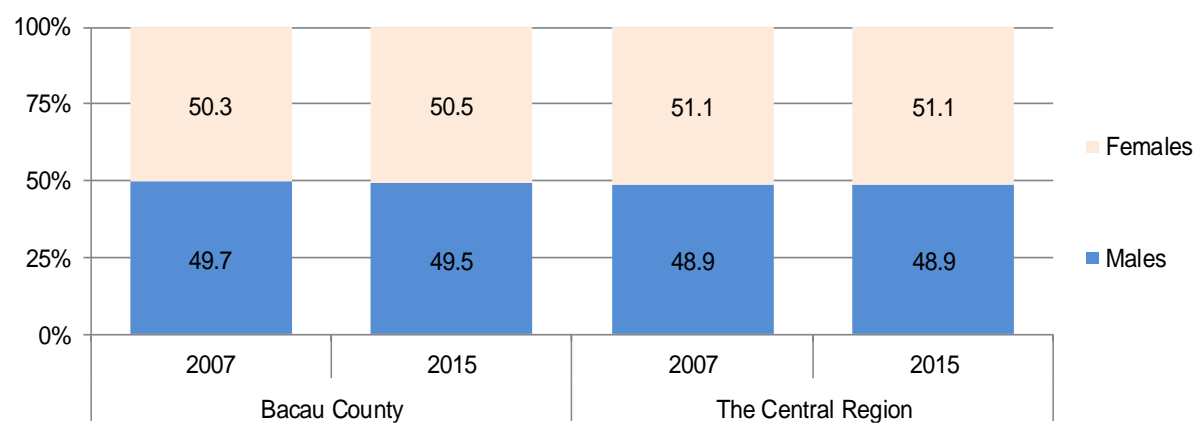

Figure no. 5: Evolution of the population according to their permanent residence on 1st January 2007 and 2015, by gender, in Bacau County and in the Central Region

Source: processing of the data collected from www.insse.ro and www.statistica.md

Thus, over the last years, we can see a decreasing trend of the male population ratio on the level of Bacau County, from 99 people in 2007 to 98 people in 2015, while in the Central Region this index has been constant (97 people).

However, when correlated to the age groups, we can notice modifications in time of this indicator. Thus, while in the case of the young population (0-14 years old) the index for male ratio in Bacau County has been constant during the whole period -105 people - , in the case of the stationary population (15-64 years old) there is a slight increase 
REGIONAL COMPARATIVE APPROACHES ON POPULATION AND MAIN DEMOGRAPHIC PHENOMENA BACAU COUNTY OF ROMANIA VERSUS THE CENTRAL REGION OF THE REPUBLIC OF MOLDOVA

(from 102 during the first 7 years subjected to this analysis to 103 during the last 2 years); in the Central Region there is a slight increase in both situations, from 105 to 106 in the case of the young population and from 98 to 99 in the case of the adult population.

As to the elder population (65 and over 65), we can notice a decreasing trend in Bacau County from 75 in 2007-2008 to 70 in 2015 ; in the Central Region this index of male ratio has a decreasing trend from 63 in 2007-2008 and 61 in 2015.

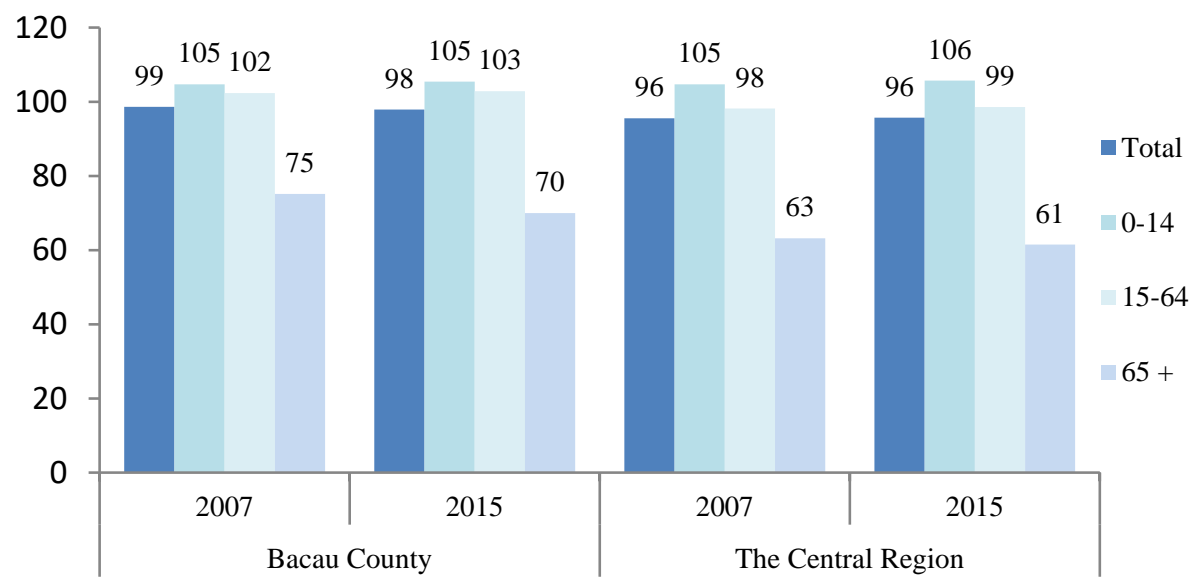

Figure no. 6: Evolution of the male ratio index in Bacau County and in the Central Region, on 1st January 2007 and 2015

Source: processing of the data collected from www.insse.ro and www.statistica.md

The comparative analysis of the two areas shows that both in Bacau County and in the Central Region there is a predominantly rural population. While in 2007-2015 we can notice a migration trend from the urban to the rural area on the level of Bacau County, in the Central Region the situation is different, with a slight decrease of the rural population.

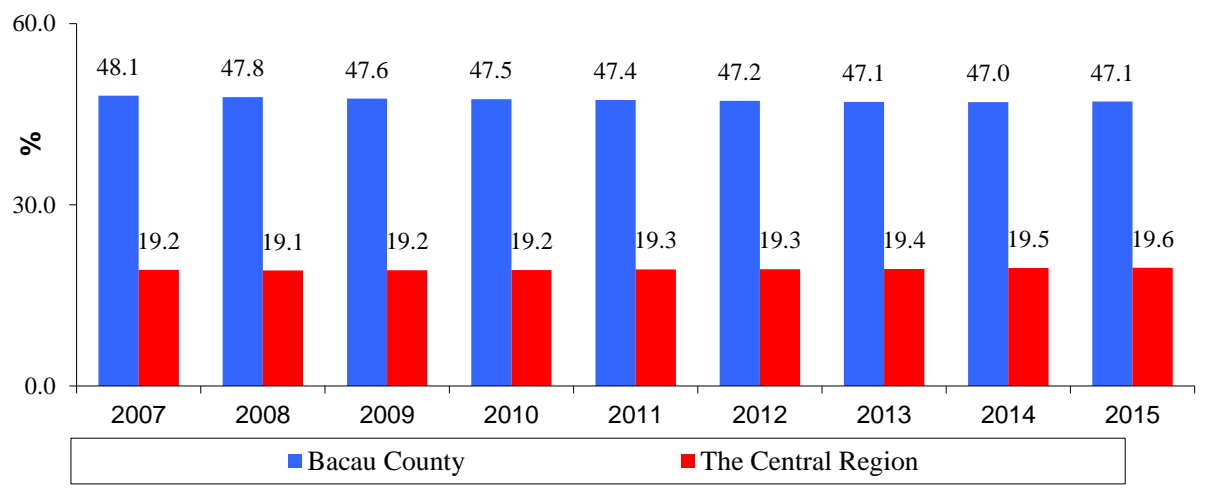

Figure no. 7: Evolution of the urbanization index in Bacau County and in the

Central Region on the $1^{\text {st }}$ of January (2007-2015) (\%)

Source: processing of the data collected from www.insse.ro and www.statistica.md

Correlated per age group, we can notice there is no clear decreasing trend of the urban population in Bacau County per major age groups. Thus, the urbanization index for the young population in Bacau County has increased from $39.8 \%$ to $41.2 \%$, while in the 
case of the adult population the same index has decreased from $52.2 \%$ to $49.4 \%$. In the case of the population over 65 , the urbanization index is on a clear increasing trend, reaching up to 4.9 percentage points higher in 2015 compared to the value registered in 2007.

The urbanization index for the young population in the Central Region has decreased slightly during the period 2007-2015; in the case of the adult population this index fluctuates, during the last year subjected to the analysis being identical to the value registered on the first year, while in the case of the elder population we can notice an increase from $15.7 \%$ to $18.8 \%$.

Statistical analysis of the indicators concerning the demographic vitality, demographic ageing and demographic dependency

In order to describe the demographic vitality of the two areas, we took into consideration:

$\checkmark$ the ratio of adult fertile women out of the total number of women;

$\checkmark$ the rate of natural increase or the natural growth rate;

$\checkmark$ the Pearl index for vitality

The ratio of adult fertile women out of the total number of women is the percentage of women aged between 15 and 49 within the total female population.

$$
g_{v f}^{f}=\frac{F_{15-49}}{F} * 100=\frac{\sum_{x=15}^{x=49} P f}{\sum_{x=0}^{\infty} P f} * 100, \mathrm{Pf}=\text { Female population }
$$

Both in Bacau County and in the Central Region the values of this indicator are over $50 \%$, clearly superior to that of the Region; however, in both situations there is a clear downward trend by $1.2 \mathrm{pp}$ in Bacau County and by $1.7 \mathrm{pp}$ in the Central Region. The values of this indicator for the urban and the rural areas of the Central Region are over $50 \%$ during the whole period subjected to the analysis, with a downward trend in both cases, the decrease being more accentuated in the urban area $(-4,8 \mathrm{pp}$ in the urban area compared to $-0,9 \mathrm{pp}$ in the rural area).

\begin{tabular}{|c|r|r|r|r|r|}
\hline & 2007 & 2008 & 2009 & 2010 & 2011 \\
\hline Bacau County & 99.1 & 97.2 & 90.8 & 85.1 & 84.3 \\
\hline The Central Region & 93.7 & 96.0 & 99.2 & 92.5 & 106.1 \\
\hline
\end{tabular}

Figure no. 8: Ratio of adult fertile women out of the total number of women in Bacau County and in the Central Region on the 1st of January (2007-2015) (\%)

Source: processing of the data collected from www.insse.ro and www.statistica.md

The situation is slightly different in Bacau County, where the ratio of fertile women out of the total number of women in the rural area is below $50 \%$ for the period subjected to 
REGIONAL COMPARATIVE APPROACHES ON POPULATION AND MAIN DEMOGRAPHIC PHENOMENA BACAU COUNTY OF ROMANIA VERSUS THE CENTRAL REGION OF THE REPUBLIC OF MOLDOVA

the analysis, although there is an increase from $45.9 \%$ in 2007 to $49.4 \%$ in 2015 (the maximal value for this period). The trend of this indicator in the urban area is similar to the situation existing in the whole County, the difference between 2015 and 2007 being of $-5.7 \mathrm{pp}$.

The rate of natural increase or the natural growth rate measures the intensity of the natural population growth and is calculated as the difference between the birth rate and the death rate.

$$
R s n=R N-R M, \quad \mathrm{RN}=\text { The birth rate; } \mathrm{RM}=\text { The death rate. }
$$

The whole period of time 2007-2015 is marked by a negative ratio of the natural growth rate in Bacau County, this rate increasing year after year and reaching a maximum negative value in 2015 (-2.5 per 1000 inhabitants). In the case of the Central Region, the first 4 years analyzed are marked by a negative natural growth ratio, while in the following 5 years the birth rate was higher than the death rate.

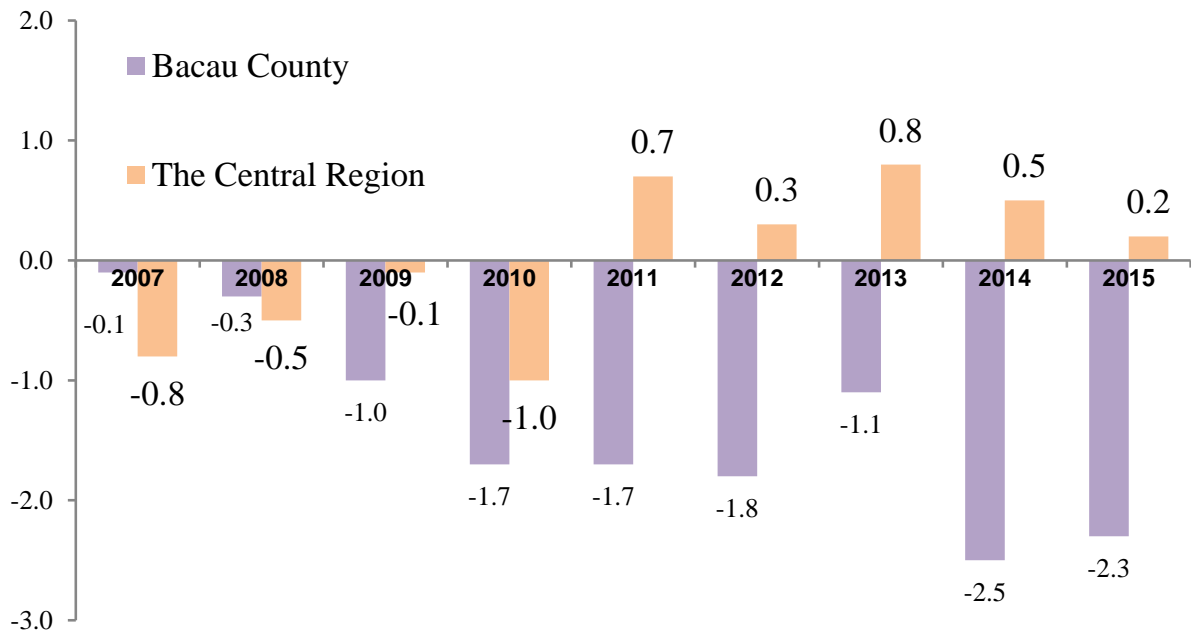

Figure no. 9: The natural growth rate in Bacau County and in the Central Region during the period of time 2007-2015

Source: processing of the data collected from www.insse.ro and www.statistica.md

The Pearl index for vitality is the ratio between live births and deaths over a certain period of time, usually a year.

$$
I_{v}=\frac{N V}{D} * 100, \mathrm{NV}=\text { Live births; } \mathrm{D}=\text { Deaths }
$$

The vitality index for Bacau County has a downward trend during the period of time subjected to the analysis, with values from $99.1 \%$ in 2007 to a minimum of $77.9 \%$ in 2015. The situation of the Central Region is favorable, with a continuous upward trend, from the value of $93.7 \%$ in 2007 to over $100 \%$ in $2011-2015$. 


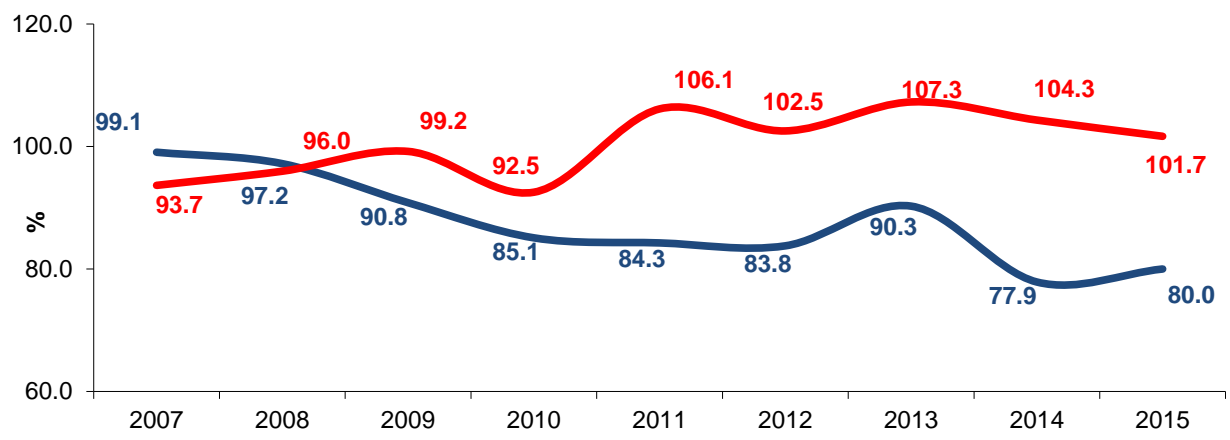

Figure no. 10: the Pearl index for vitality in Bacau County and in the Central Region during the period of time 2007-2015 (\%)

Source: processing of the data collected from www.insse.ro and www.statistica.md

The demographic ageing index shows an increase in the elder population at the expense of the young population. It is calculated as the ratio between the population aged 65 and over 65 and the young population (0-14 years old).

$$
I_{i d}=\frac{P_{65+}}{P_{0-14}} * 100=\frac{\sum_{x=65}^{\infty} P x}{\sum_{x=0}^{x=14} P x}, \mathrm{P}=\text { population }
$$

The literature says that values lower than $40 \%$ of this indicator shows a young population, values between $40-44 \%$ show a middle-aged population while values of 48 $52 \%$ are characteristic for an aged population.

Calculated on the level of Bacau County for the period of time 2007-2015, this index shows the existence of an aged population, with a minimum value of $75.8 \%$ in 2007 up to a maximum value of $87.1 \%$ in 2015 .

Considering the rural and the urban areas separately, we can also notice an alarming ageing process of the population, with values over $70 \%$, the ageing index in the rural areas being higher than the ones in the urban areas for the period 2007-2013, while during the last 2 years there were higher ageing indexes in the urban area compared to the rural area.

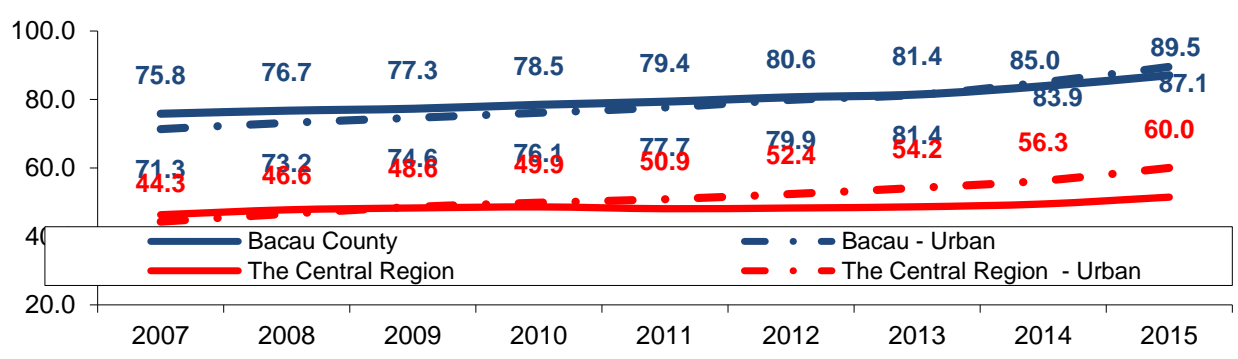

Figure no. 11: The ageing index in Bacau County and in the Central Region during the period of time 2007-2015 (\%)

Source: processing of the data collected from www.insse.ro and www.statistica.md 
REGIONAL COMPARATIVE APPROACHES ON POPULATION AND MAIN DEMOGRAPHIC PHENOMENA BACAU COUNTY OF ROMANIA VERSUS THE CENTRAL REGION OF THE REPUBLIC OF MOLDOVA

The demographic ageing indicators for the Central Region had an upward trend during the period of time subjected to the analysis, with values under $50 \%$ for the period 20072014 and with a value of $51.5 \%$ during the last year. While during the first 2 years the demographic ageing indicators in the rural areas of the Region were higher than in the urban areas, during the period 2009-2015 the situation was reversed.

Calculated per gender, on the level of Bacau County, we can notice great differences between the ageing indexes for the female population for the male population, one more evidence for the feminization of the population ageing. The values of this index for the male population in Bacau County are in the interval $63.6 \%$ and $69.9 \%$, while in the case of the female population the values are very high, varying between $88.6 \%$ in 2007 and $97.4 \%$ in 2013 , the last two years analyzed being marked by values over $100 \%$.

While the ageing indicators for the female population in the rural area of Bacau County are higher than the ones in the urban area during the whole period of time, the indicators for the male population in the rural area are higher only for the period of time 20082012.

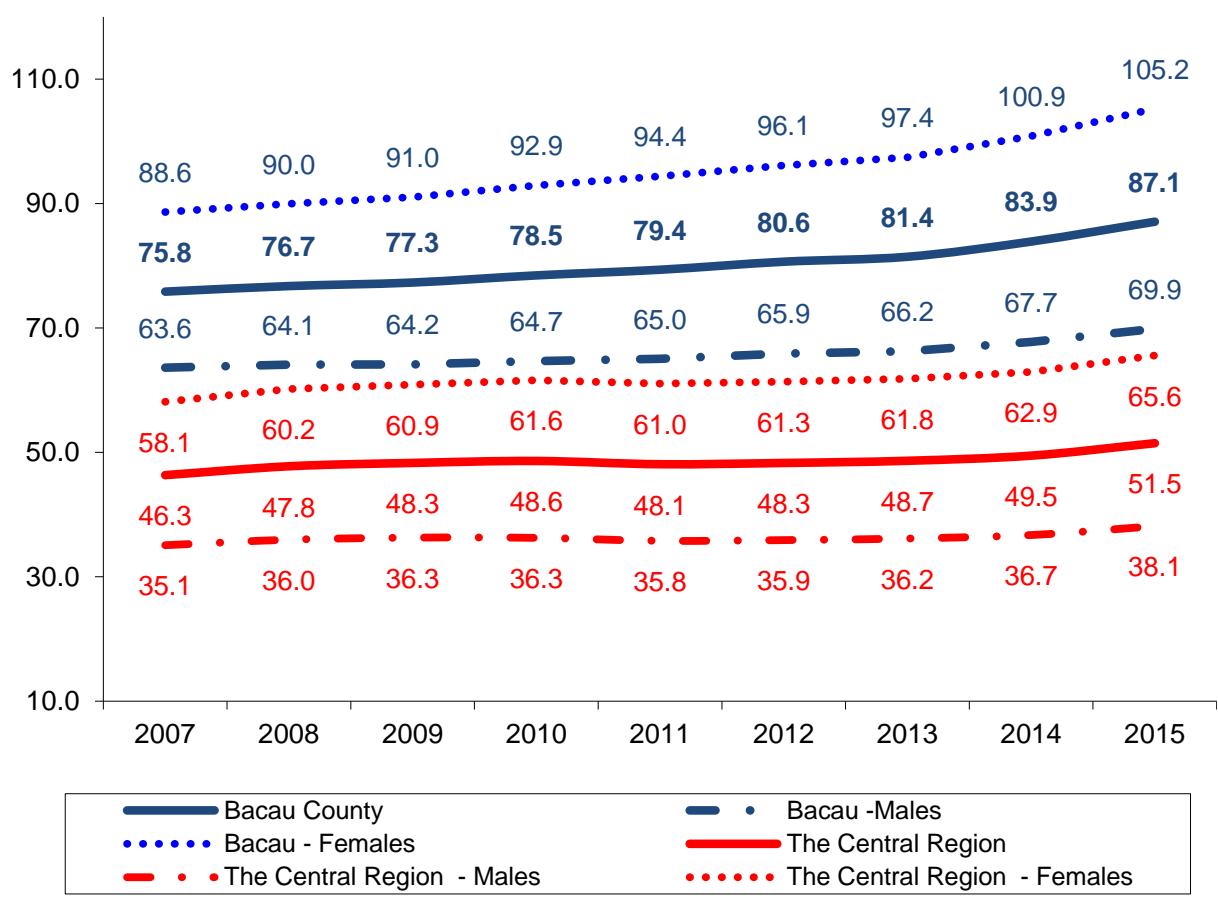

Figure no. 12: The demographic ageing index per gender in Bacau County and in the Central Region during the period of time 2007-2015 (\%)

Source: processing of the data collected from www.insse.ro and www.statistica.md

In the Central Region too, the demographic ageing indicators for the female population are much higher than the ones for the male population. In the case of men, this index increases from $35.1 \%$ in 2007 to $38.1 \%$ in 2015 , while in the case of the female population the increase is even higher, from $58.1 \%$ during the first year analyzed to $65.6 \%$ during the last year.

The seniority index is the ratio between the number of people aged 80 and over 80 and the number of people aged 65 and over 65. 


$$
I_{s}=\frac{P_{80+}}{P_{65+}} * 100=\frac{\sum_{x=80}^{\infty} P x}{\sum_{x=65}^{\infty} P x} * 100, \mathrm{P}=\text { population }
$$

In Bacau County there is an increase of the seniority index from $16.6 \%$ in 2007 to $23.4 \%$ in 2015 , the values registered in the rural areas being higher than in the urban areas, the values for the female population being higher than the ones for the male population.

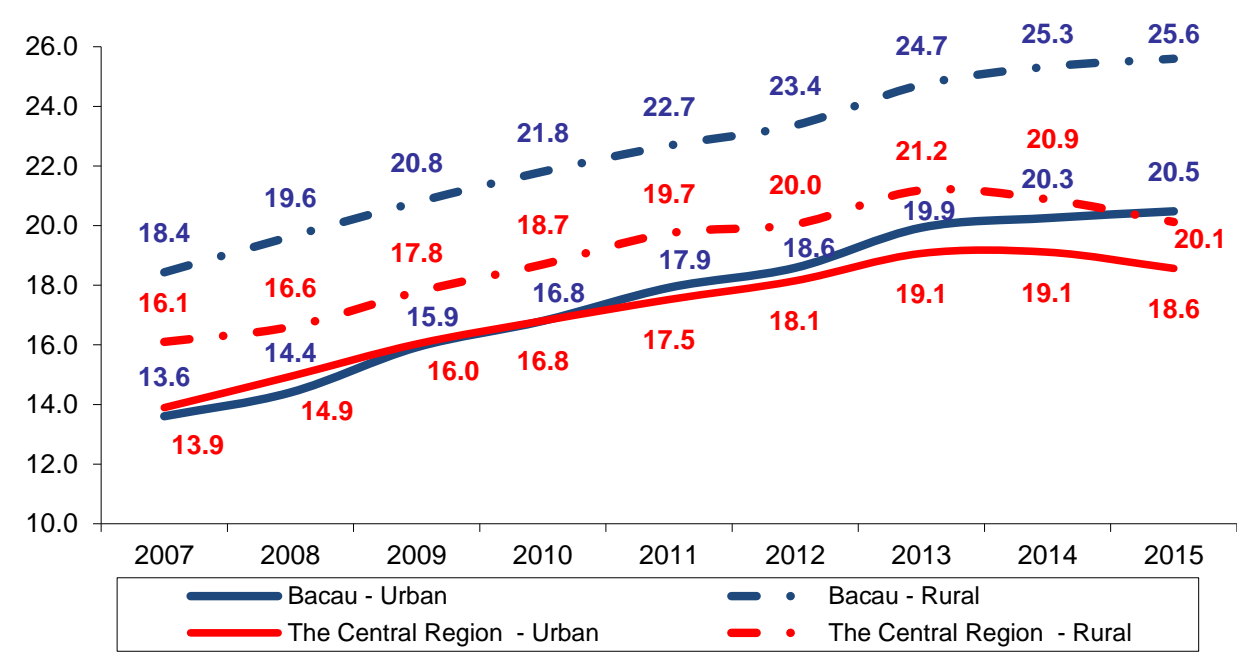

Figure no. 12: The seniority index in the rural and the urban areas in Bacau County and in the Central Region during the period of time 2007-2015 (\%)

Source: processing of the data collected from www.insse.ro and www.statistica.md

In the Central Region there are fluctuations of this index, with an upward trend in the period $2007-2013$, from $15.7 \%$ to $20.8 \%$, followed by a downward trend during the last 2 years.

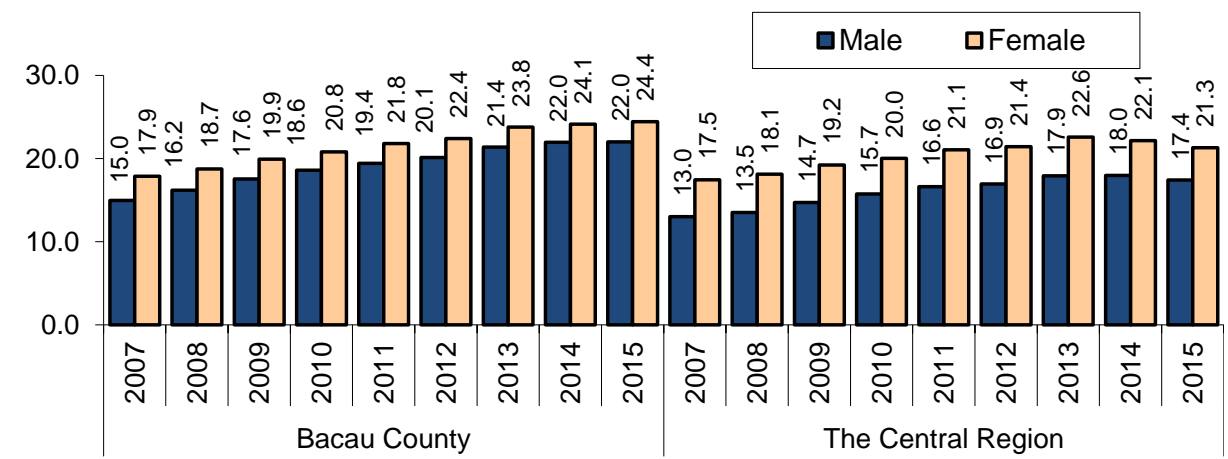

Figure no. 13: The seniority index per gender in Bacau County and in the Central Region during the period of time 2007-2015 (\%)

Source: processing of the data collected from www.insse.ro and www.statistica.md

In the Central Region, the ratio of people aged over 80 out of the population aged over 65 and over was higher in the rural area than in the urban area in 2007-2015. In the case of the Central Region of the Republic of Moldova there is also a considerable ratio 
REGIONAL COMPARATIVE APPROACHES ON POPULATION AND MAIN DEMOGRAPHIC PHENOMENA BACAU COUNTY OF ROMANIA VERSUS THE CENTRAL REGION OF THE REPUBLIC OF MOLDOVA

of female population aged 80 and over 80 , much higher than in the case of the male population, the disparity between these seniority ratios reaching up to $4.6 \mathrm{pp}$.

The demographic dependency ratio emphasizes the „pressure” of the young population aged 0-14 and of the population aged 65 and over 65 on the active population (aged 15$65)$.

$$
R D D=\frac{P_{0-14}+P_{65+}}{P_{15-64}} * 100=\frac{\sum_{x=0}^{14} P_{x}+\sum_{x=65}^{\infty} P x}{\sum_{x=15}^{x=64} P x} * 100, \mathrm{P}=\text { population }
$$

We are discussing here a potential support ratio. The actual economic dependency ratio involves the active population and the inactive population, irrespective of the age. The demographic dependency in Bacau County has an downward trend, from 44.8 young and elder people per 100 adult people in 2007 to 42.6 people in 2015 ; the same trend was registered in the Central Region (from 41.5 young and elder people per 100 adult people in 2007 to 36.5 people in 2015).

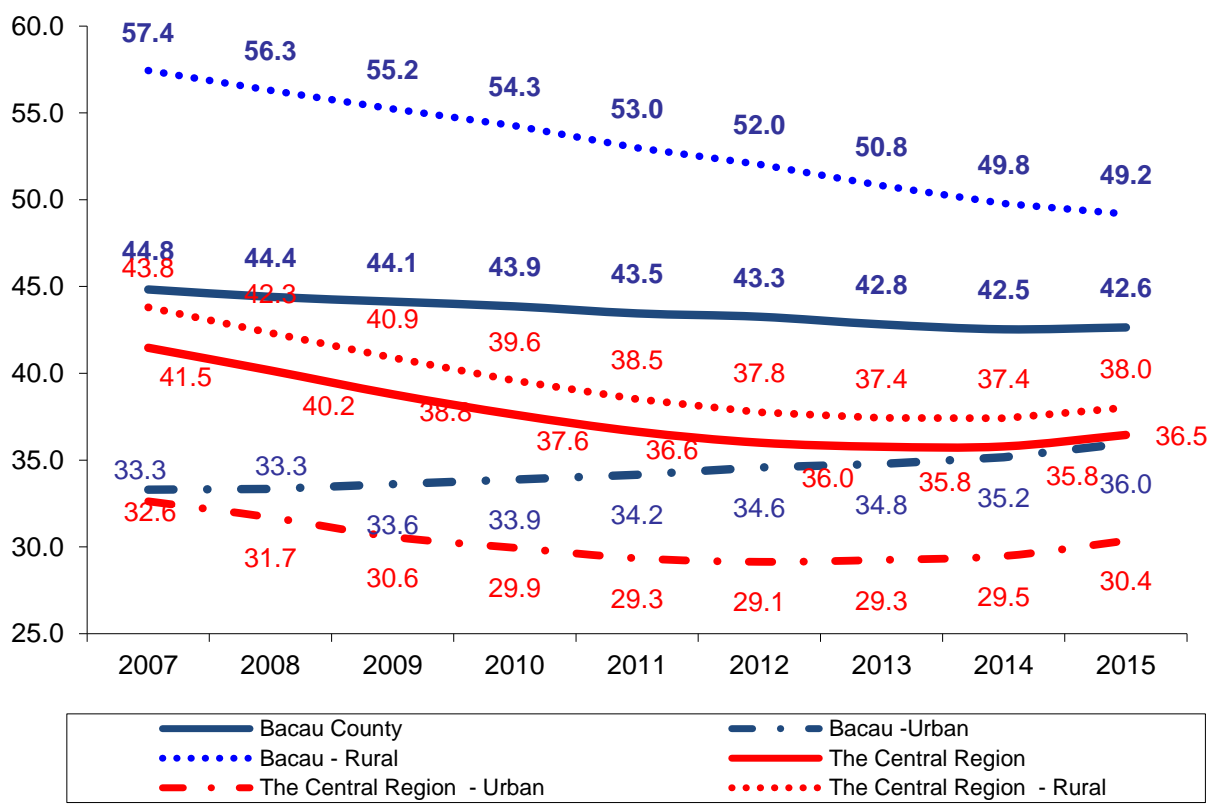

Figure no. 14: The demographic dependency report in the rural and the urban areas in Bacau County and in the Central Region during the period of time 20072015

Source: processing of the data collected from www.insse.ro and www.statistica.md

As we can notice in figure 14, the demographic dependency ratios in the rural area are higher than the phenomenon registered in the whole area, in the case of both regions subjected to the analysis, the difference between the rural and the urban areas reaching the value of 6.6 young and elder people per 100 adult people in 2015 in Bacau County, while in the Central Region the difference is even greater than 7.6 people.

\section{Conclusion}

The structure per age of the population in Bacau County and in the Central Region shows a slow, continuous demographic ageing process caused mainly by the decrease of birth rate which led to a decrease of the young population (aged 0-14), while the 
elder population aged 65 and over 65 increased. We can also notice a more accentuated ageing process in the case of the female population as well as in the case of the rural population. The effects of the ageing process weigh on the seniority indicators, which have an upward trend during the period of time subjected to the analysis.

\section{References}

Jaba, Elisabeta (1998), Statistică, Bucureşti, Editura Economică.

Mihăescu, Constanţa (2003), Analiza statistico-demografică: teorie și aplicații, Bucureşti, Editura Economică.

Vert, Constantin (1995), Analiza geodemografică - Manual practic, Universitatea de Vest din Timișoara.

INS, Statistics available at www.insse.ro

BNS, Statistic available at www.statistica.md 